\title{
Eric Eigenmann, «"Pourquoi donc suis-je ainsi?” La réponse de Fortunio. Introspection chez Alfred de Musset»
}

\section{Valentina Ponzetto}

\author{
(2) OpenEdition \\ Journals \\ Edizione digitale \\ URL: http://journals.openedition.org/studifrancesi/27861 \\ DOI: 10.4000/studifrancesi.27861 \\ ISSN: 2421-5856

\section{Editore} \\ Rosenberg \& Sellier

\section{Edizione cartacea} \\ Data di pubblicazione: 31 décembre 2006 \\ Paginazione: 626 \\ ISSN: 0039-2944

\section{Notizia bibliografica digitale} \\ Valentina Ponzetto, «Eric Eigenmann, «"Pourquoi donc suis-je ainsi?” La réponse de Fortunio. \\ Introspection chez Alfred de Musset» », Studi Francesi [Online], 150 (L | III) | 2006, online dal 30 \\ novembre 2015, consultato il 08 novembre 2020. URL : http://journals.openedition.org/studifrancesi/ \\ 27861 ; DOI : https://doi.org/10.4000/studifrancesi.27861
}

Questo documento è stato generato automaticamente il 8 novembre 2020.

\section{c) (†) $\odot$}

Studi Francesi è distribuita con Licenza Creative Commons Attribuzione - Non commerciale - Non opere derivate 4.0 Internazionale. 


\title{
Eric Eigenmann, «"Pourquoi donc suis-je ainsi?" La réponse de Fortunio. Introspection chez Alfred de Musset»
}

\author{
Valentina Ponzetto
}

\section{NOTIZIA}

ERIC EIGENMANN, «"Pourquoi donc suis-je ainsi?” La réponse de Fortunio. Introspection chez Alfred DE MUSSET», in Le Drame du XVI' siècle à nos jours, sous la direction de Philippe Baron, Éditions Universitaires de Dijon, 2004, pp. 105-118.

1 A differenza degli eroi del teatro classico, i cui dilemmi deliberativi vertono in genere sul tema del «che fare?», o «come fare?», i protagonisti del teatro di Musset sono estremamente determinati nelle loro azioni, e tuttavia tormentati da un più profondo interrogativo esistenziale: «qui suis-je?» o «pourquoi suis-je ainsi?». In questo articolo Eric Eigenmann analizza le forme del discorso autoriflessivo dei personaggi mussettiani nelle pièces fino al 1835, per metterne in luce le particolarità e le implicazioni estetiche e biografiche all'interno dell'opera del drammaturgo.

2 Una prima parte dell'articolo, attraverso l'analisi stilistica degli elementi ricorrenti nei monologhi e soliloqui dei protagonisti (formulazioni impersonali o alla terza persona, generalizzazioni e antonomasie, espressioni verbali indicanti l'iterazione, quali l'imperfetto, il presente storico, l'infinito) mostra come la coscienza del sé si sviluppi in essi nella continua articolazione fra oggettivo e soggettivo, collettivo e individuale. La loro identità si costruisce dunque per opposizione ad un'alterità collettiva, in una dialettica tipicamente romantica che oppone al mondo un io di unicità assoluta, la cui differenza è rivendicata come motivo d'orgoglio e insieme vissuta come sofferenza. Da questo sentimento deriva, in alcuni eroi di Musset, e in particolare in Cœlio, Fantasio e 
Lorenzaccio, il desiderio di diventare altro da sé, desiderio che, secondo il critico, quando è sul punto di realizzarsi porta il personaggio a perdersi definitivamente, o addirittura a morire.

Nel corpus esaminato l'unico personaggio che sfugge a questa logica tragica e pessimista è Fortunio, il giovane protagonista de Le Chandelier, che riesce, nel corso della pièce, a conquistare l'amore di Jacqueline, prendendo letteralmente il posto del capitano Clavaroche, nonché di Maître André, il marito della donna. Al caso particolare di questo personaggio, e segnatamente all'analisi del suo lungo monologo del terzo atto, laddove egli prende coscienza di sé e dei propri sentimenti, è dedicata la seconda metà dell'articolo, che prende le mosse dalla prima per poi staccarsene quasi completamente. Facendo appello questa volta ad elementi di critica biografica e psicanalitica Eigenmann mostra come Fortunio realizzi il desiderio impossibile di tanti suoi fratelli e forse di Musset medesimo: diventare altro da sé, e più precisamente diventare il padre, l'uomo adulto sicuro dell'amore di una donna. 